\title{
AN ANEROID CALORIMETER
}

\author{
By H. C. Dickinson and N. S. Osbome
}

\section{CONTENTS}

INTRODUCTION.

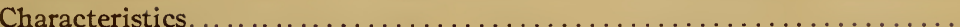

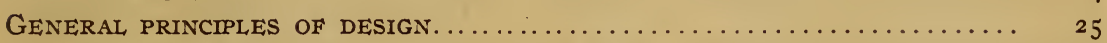

Equalization of temperature................................ ${ }^{25}$

Control of jacket temperature ............................... 25

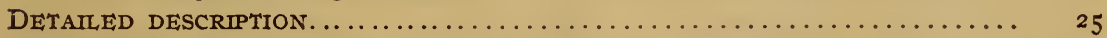

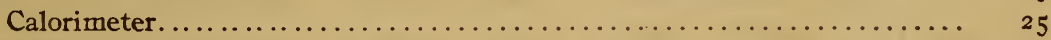

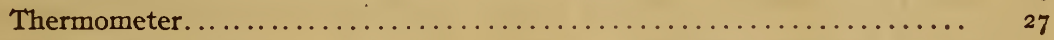

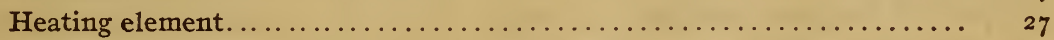

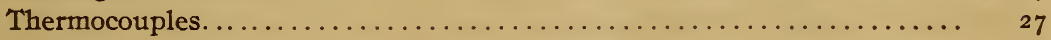

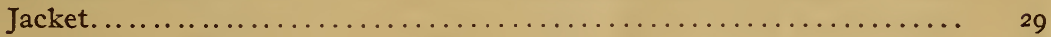

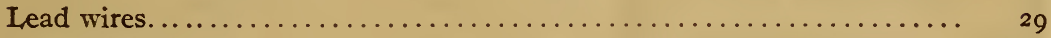

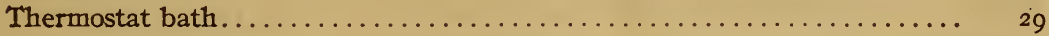

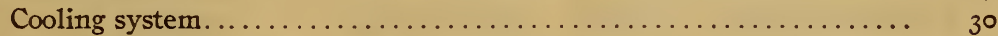

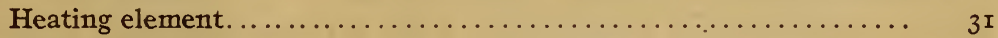

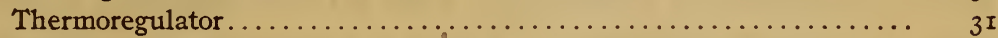

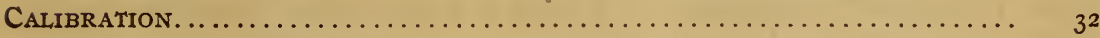

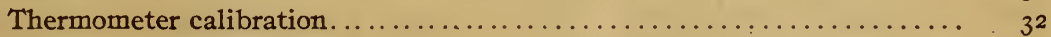

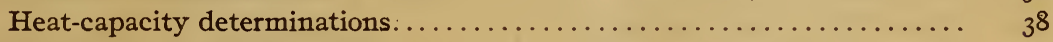

Calibration of thermocouples.............................. 39

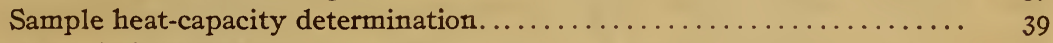

Method of computation of results..............................

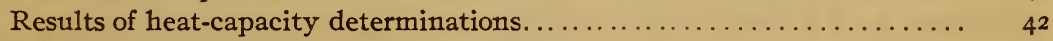

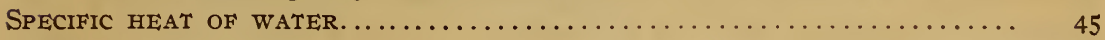

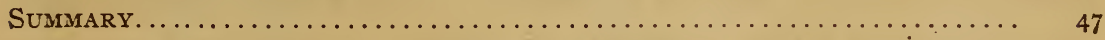

\section{INTRODUCTION}

Several years ago the feasibility of making use of a calorimeter consisting entirely of metal, depending upon metallic conduction instead of the stirring of a liquid, was considered at the Bureau. The high thermal conductivity of copper seemed to offer a prospect of success, and with a view to testing its performance such a calorimeter was built at about the time that the work of Eucken ${ }^{1}$ 
and of Nernst, Koref, and Lindemann, ${ }^{2}$ utilizing the same principle, became known. This instrument was described by D. R. Harper $3{ }^{3}{ }^{3}$ in a paper before the American Physical Society in April, 1913. Meanwhile this principle has also been applied by Féry. ${ }^{4}$ The original calorimeter built at the Bureau, however, differed materially from these, in that both a thermometric element and a heating element were imbedded within the mass of the metal itself. This earlier calorimeter was in the form of a hollow cylinder of cast copper, Io cin in diameter, ro $\mathrm{cm}$ high outside, and having a wall thickness of $\mathrm{x} \mathrm{cm}$. The heating element and the resistance thermometer element were laid in grooves, insulated with mica, and covered by copper strips in the manner described later, except that the two coils were laid in the same deep groove with a copper strip between them, instead of in separate grooves as in the later instrument. Although the cast copper was quite impure, thus having a much lower thermal conductivity than pure copper, it became evident at once that the method was not only capable of considerable precision, but was applicable to a wide range of temperature and to a wide variety of problems which could hardly be undertaken with calorimeters of any other single type.

Characteristics.-Upon undertaking a number of calorimetric problems in connection with an investigation of refrigerants, it became necessary to adopt a calorimeter suitable for use under unusual conditions. The "aneroid calorimeter" combines the following characteristics: (I) It is applicable to both solids and liquids even under high pressure; (2) the same instrument, without any changes, can be used over a very wide range of temperature, and by suitably adapting the jacket and the liquid used therein, this range can be extended to the lowest temperatures obtainable and up to $+200^{\circ} \mathrm{C}$ or higher; (3) the heat capacity of the calorimeter and contents can be measured over small temperature intervals, thus approximating the heat capacity at a definite temperature; (4) the troublesome correction due to evaporation of a calorimetric liquid and to the energy supplied by the stirring device are eliminated.

\footnotetext{
2 Nernst, Koref, and Lindemann, Sitzungsberichte der Königlich Preussischen Akademie der Wissenschaften, 1910, p. 247.

${ }^{8}$ Harper, Physical Review (2), 1, p. 469; I913.

- Firy, Comptes Rendus, 154, p. 69r; Igr2.
} 
Bulletin Bureau of Standards, Vol. 12

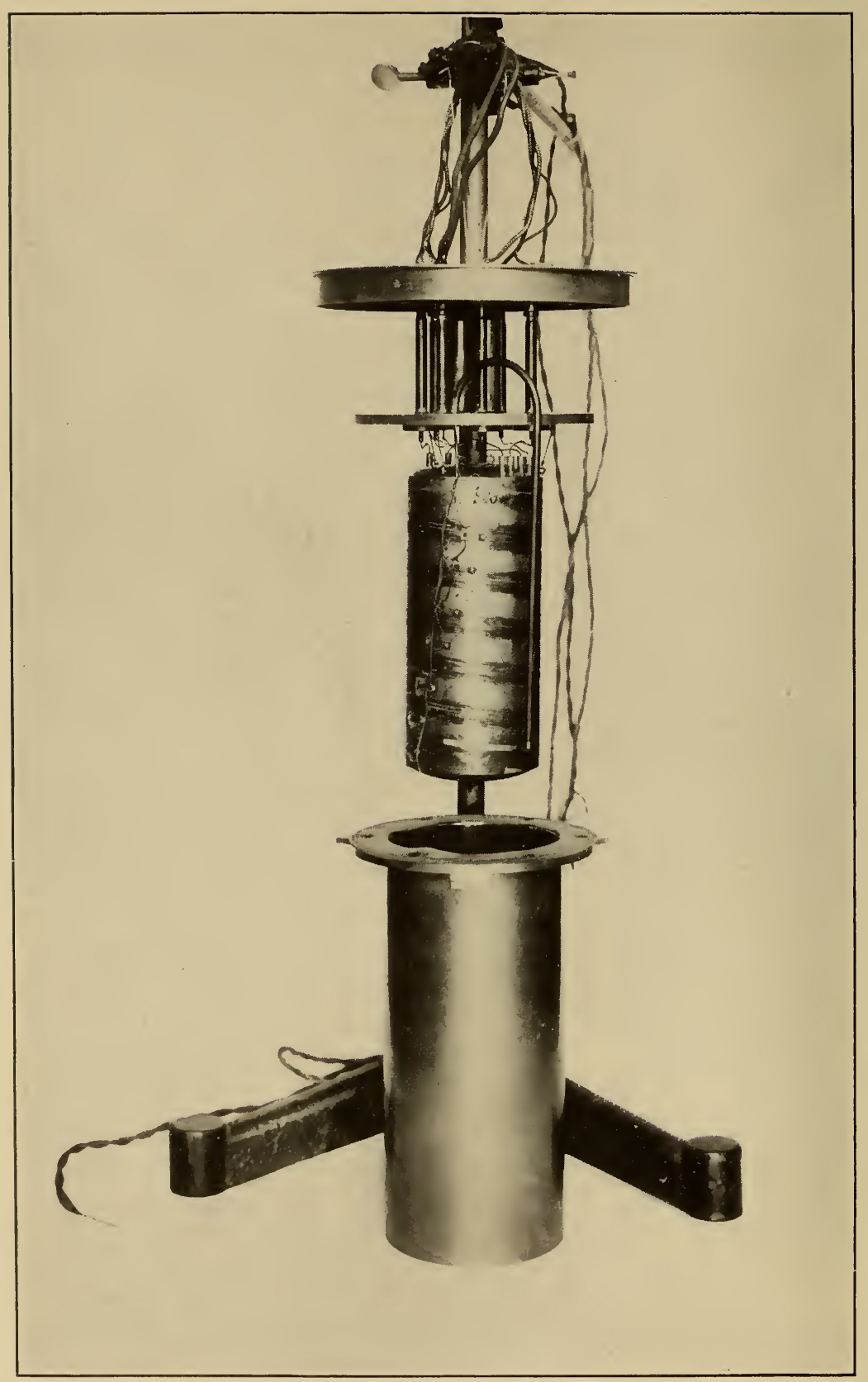

FIG. 2.-Calorimeter and jacket 


\section{GENERAL PRINCIPLES OF DESIGN}

Equalization of Temperature.-The factor of prime importance in a calorimeter of this type is the rapid equalization of temperature over the surface of the calorimeter and throughout the entire mass of material. To provide for this, the material of the calorimeter should have as high thermal conductivity as possible, and the design should be such as to facilitate equalization of temperature.

A cylinder of copper of about $8 \mathrm{~cm}$ diameter, $18 \mathrm{~cm}$ length outside, and $5 \mathrm{~mm}$ wall thickness forms a highly conducting container within which can be inclosed either solids or liquids. Determination of the mean temperature of this cylinder is effected by measuring the electrical resistance of a platinum wire insulated with mica and wound at the bottom of a helical groove, which is then filled in with a copper strip. The energy required for heating is supplied electrically by means of a constantan wire similarly mounted in a second helical groove.

Control of Jacket Temperature.-The calorimeter is suspended by fine steel wires within a thin walled brass vessel or jacket which can be so closed as to permit total immersion in liquid. In order to control its temperature, the jacket containing the calorimeter is immersed in a stirred bath containing a carbon dioxide expansion cooling coil, an electric heating coil, and a coil of copper tubing forming the bulb of a thermostat. The stirrer is so placed as to give rapid circulation of the liquid, particularly around the heating and cooling coils and thermostat bulb.

The whole bath is surrounded by a thick layer of insulating material to adapt it for use at low temperatures.

\section{DETAILED DESCRIPTION}

Calorimeter.-The copper calorimeter, as shown in Figs. 2 and 3 , was turned from a solid block of electrolytic copper. The helical grooves, four in number, each making about four turns around the cylinder, were milled with a concave bottom. The platinum wire and the flat constantan wire were wound in.the bottom of these grooves and insulated with overlapping mica strips. A rectangular copper strip, concave on one side, was driven in place so as to compress the edges of the mica strips but leave the 


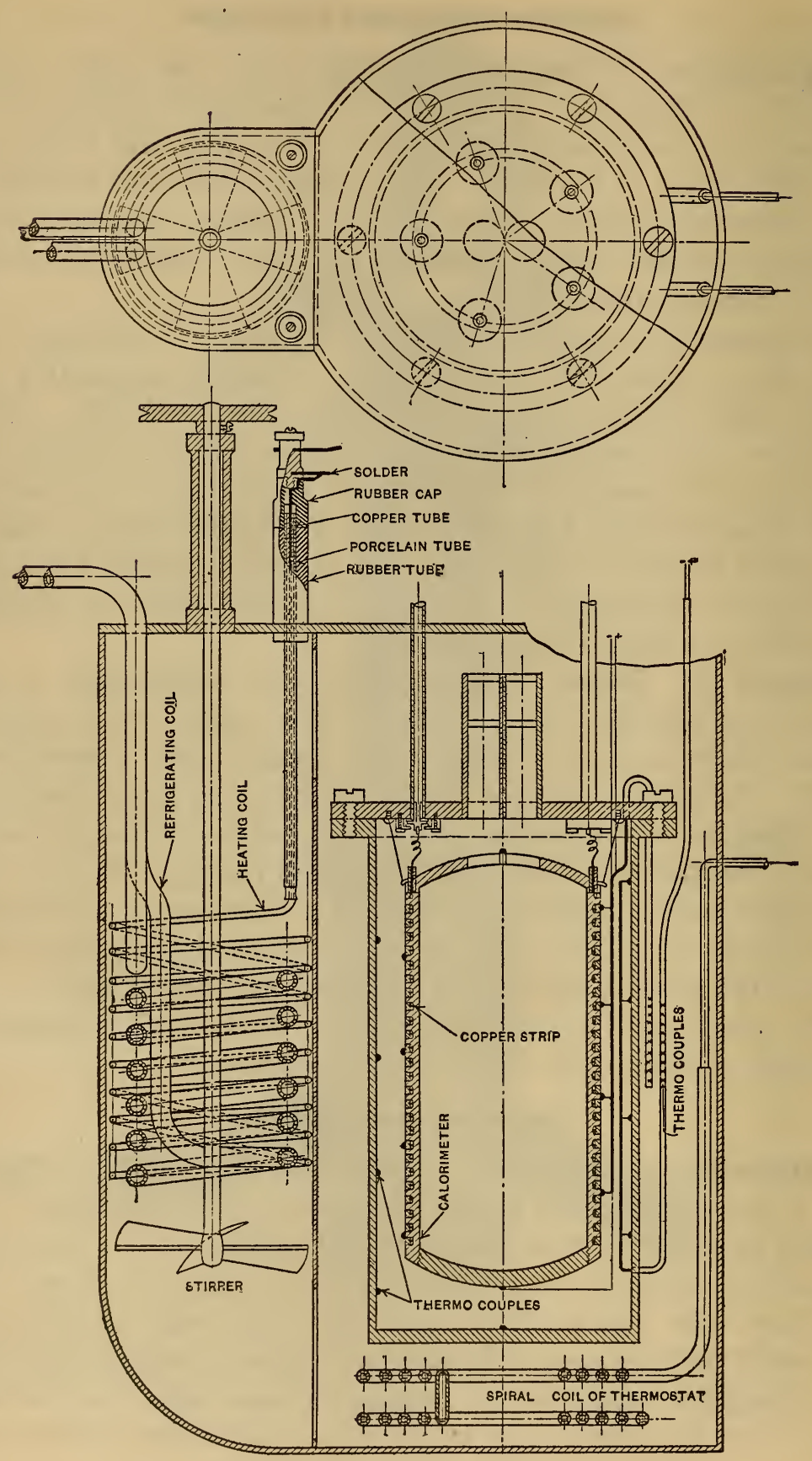

FIG. 3.-Assembly drawing of calorimeter and jacket 
wire free, as shown in Fig. 4. Each of the two wires occupies two grooves, going down in one and back in the adjacent one, so that both the thermometer and the heating element are distributed quite uniformly through the entire cylindrical portion of the calorimeter. After the wires and copper strip were in place the latter was sweated in with pure tin and the surface turned true and nickel plated. Unfortunately, after this was done a.defect developed in the thermometer coil, making it necessary to remove a part of this coil, thus removing a portion of the nickel plating.

Thermometer.--The resistance thermometer consists of a $0.1 \mathrm{~mm}$ platinum wire about 3 meters long, having a resistance at $0^{\circ} \mathrm{C}$ of 3 r.or ohms. The method of winding, while avoiding direct pressure of the copper covering, does leave the wire subject to some irregularities of mechanical strain due to elasticity of the mica strips, as well as to differential thermal expansion. . It was found that the resistance of the thermometer at a given temperature (e. g., ice point) changed considerably during the initial calibration but later became more nearly constant.

Heating Element.-The heating element consists of a constantan wire of the same length as that of the thermometer Fig. 4.-Detail of thermometer wire and having a resistance of about 9.2 and heating coil construction ohms. This wire was rolled flat before winding and was wound in the same manner as the thermometer coil. The connections to both heater and thermometer were brought out from the calorimeter through short porcelain tubes within copper tubes.

Thermocouples.-In order to make corrections for thermal leakage between calorimeter and jacket it is necessary to know the 
difference in temperature between the surface of the calorimeter and that of the jacket. A careful survey of the distribution of temperature on both of these surfaces, when the temperatures were changing, disclosed the fact that the distribution was not uniform over the surface of either calorimeter or jacket. In order conveniently to measure, at any given instant, the difference between the mean temperatures of the surfaces, two sets of copper constantan thermocouples, ro in each set connected in series, were used. The junctions applied to the surfaces were soldered to thin copper plates each about $4 \mathrm{~mm}$ square, while the two sets of complementary junctions were imbedded in paraffin in copper tubes. These junctions were mounted as shown in Fig. 2 and diagrammatically in Fig. 3. Ten junctions of one set were distributed over the surface of the calorimeter and held in place by small phosphor bronze clips and : sulated with mica, and the corresponding ro junctions of the or er set were similarly mounted on the inner surface of the jacket. The copper tubes containing the two complementary sets were attached one to the cover and the other to the side of the jacket and extended into the surrounding liquid, where they were clamped side by side in a split-copper bar. The calorimeter and the jacket cover can thus be removed together without disturbing any of the junctions, except the single one on the cover.

One set of thermocouples indicates the temperature difference between a point in the liquid and the surface of the calorimeter while the other set indicates the temperature difference between the same point in the liquid and the surface of the jacket. By suitably connecting the terminals of the two sets, since the junctions in the liquid are at the same temperature, the temperature difference between the calorimeter surface and the jacket surface can be measured. The two sets of couples can be read either independently or combined, direct or reversed. For the purpose of setting its zero the galvanometer can be connected to a coil free from thermoelectromotive forces and having the same resistance as the couples.

The sensibility of the arrangement could be varied in four steps by means of suitable series and shunt coils so chosen as to preserve critical damping of the galvanometer. All the operations of 
changing connections could be quickly performed by means of a switchboard, the arrangement of which is shown in Fig. 5 .

Jacket.-The construction of the jacket of the calorimeter is shown in Figs. 2 and 3.

Electrical connections and inlet tubes, when required, are brought out through the cover from which the calorimeter is suspended so that when the body of the jacket is removed the calorimeter is accessible for adjustment or changing its contents.

The material to be used for a leak-proof gasket between the jacket and its cover depends upon the nature of the liquid used in the jacket. When gasoline is used, a satisfactory gasket is one

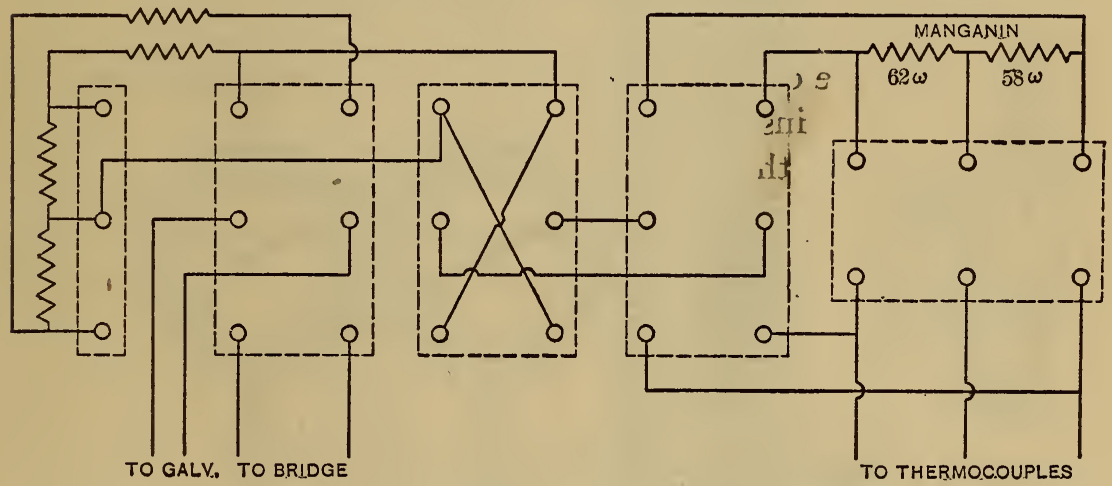

Fig. 5.-Diagrammatic representation of circuits

made by impregnating cloth with a compound of gelatin and glycerin.

Lead Wires.-The method used for the insulation of the leads to the thermometer and the heating coil is shown in Fig. 3. The leads to the thermocouple were drawn through copper tubes which were then filled with wax to close the opening and exclude condensed moisture.

Thermostat Bath.-The essential details of construction of the thermostatically controlled bath are shown in Fig. 3. The brass vessel serving as container for the liquid is supported within a cork-filled box and is supplied with a cover of 2-inch cork board to minimize the transfer of heat between the liquid and the surroundings. The offset contains the stirrer, cooling coil, and heacing coil. 
Cooling system.-The cooling system consists of a copper expansion coil containing about 2 meters of tubing, $8 \mathrm{~mm}$ in diameter, and connected to a carbon dioxide compression system. It was found that great care was necessary in drying the carbon dioxide and freeing it from oil in order that it should not clog in the expansion coil or at the very small throttle valve which was used. A drier in the high-pressure line, containing fused calcium chloride, together with a filter of glass wool and an oil trap, served

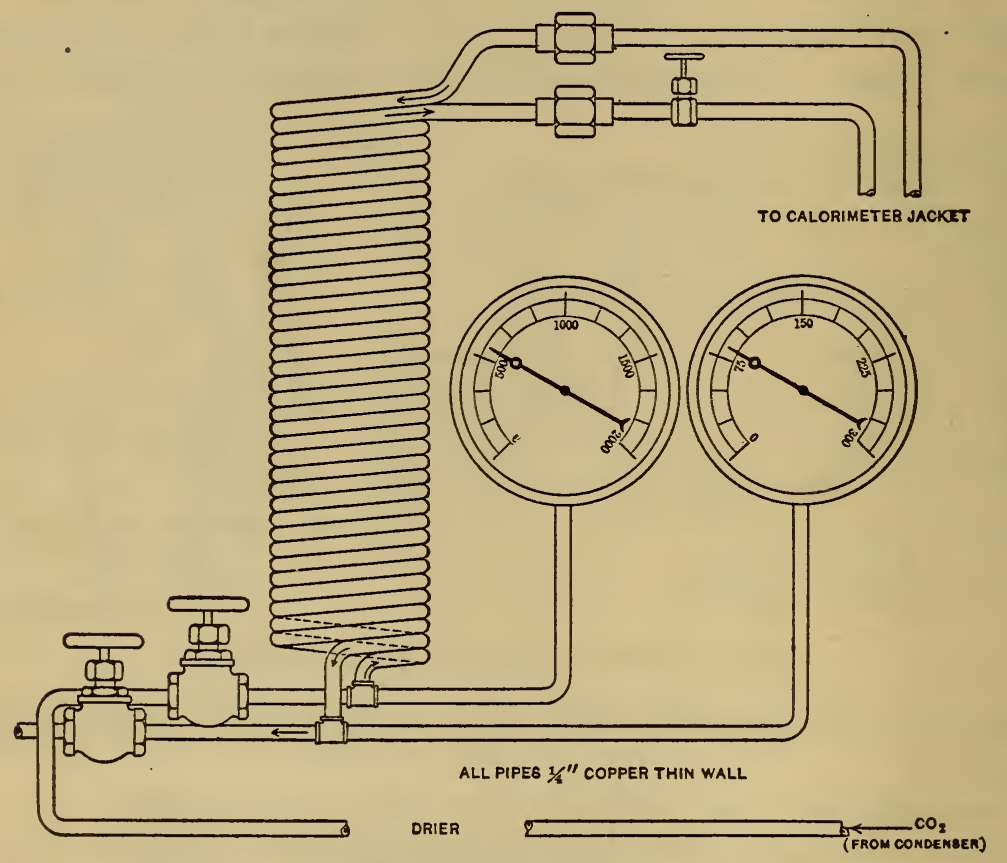

FIG. 6.-Heat exchanger

to eliminate moisture and oil from the liquid carbon dioxide. Just outside the thermostat bath the incoming and outgoing currents of carbon dioxide pass in opposite directions through a heat exchanger shown in Fig. 6. This exchanger consists simply of two copper pipes in the shape of adjacent helical spirals soldered together throughout their length and covered with cork board for thermal insulation. With the present arrangement it is possible to maintain constant to within a few thousandths of a degree any desired temperature between $-55^{\circ}$ and $+40^{\circ} \mathrm{C}$. 
Heating Element.-The heating coil, shown in Fig. 3, consists of a length of asbestos covered "advance" resistance wire, which, for protection from the liquid, is inclosed in a copper tube of about $0.3 \mathrm{~mm}$ wall thickness. By alternate drawing, annealing, and stretching, a copper tube is reduced to the desired thickness and to as small a size as will readily permit introduction of the insulated wire. Then the wire, which has received several coats of thin shellac baked on over the asbestos covering, is threaded into the tube, which is then passed through a draw plate bringing it down into better contact with the insulated wire.

This type of coil has proven very satisfactory, as it has a small heat capacity and will dissipate a very large amount of energy without excessive heating, and is also easy of construction. Its use has greatly improved the behavior of the thermostat on account of the small amount of heat remaining in the coil when the heating current is cut off. The lead wires to the heating coil, as well as all other electric leads, are carefully covered with waterproof material (Ozo-

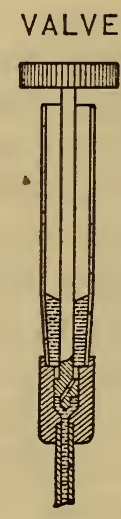

FIG. 7.-Detail of thermoregulator

kerite) for some distance from the calorimeter to prevent serious electric leakage through the moisture condensed on the cold portion of the wires.

Thermoregulator. - The temperature control is secured by means of a thermoregulator, consisting of a coil of about 2 meters of 6-mm copper tubing wound in a double spiral and placed near the bottom of the container. From each end of this copper tube a smaller copper tube extends up and out through the wall of the containing vessel, as shown in Fig. 3. One end opens through a small needle valve into a glass tube, and the other into a glass thermostat head, shown in Fig. 7. The thermoregulator is filled with toluol, and the bottom of the glass $U$ tube with a small amount of mercury serving to make and break an electric contact operating, through a relay, a shunt in the main electric-heating circuit. 
A regulator of this type is convenient for the present purpose, since whenever a desired temperature is reached the regulator may be set to maintain this temperature by opening and then closing the needle valve.

\section{CALIBRATION}

Thermometer Calibration.-The thermometer built into the copper calorimeter was found by preliminary calibration not to have the characteristics of the ordinary platinum resistance thermometer. Hence, a rather extended study of its behavior was necessary. The finished calorimeter was inclosed in a close-fitting copper container which could be immersed in steam, water, and other comparison media. A series of measurements of the resistance of the thermometer were then made in ice and steam, and a few in a mixture of solid carbon dioxide and gasoline. This latter test point was not satisfactory for the comparison of so bulky a thermometer because of the variations in temperature of the bath itself due to hydrostatic pressure. This difference was nearly $0^{\circ} \mathrm{I} \mathrm{C}$ between the top and bottom of the thermometer. The main object of this latter test was to determine the constancy of the ice and steam points of the thermometer after exposure to quite low temperatures.

The observations made in this way indicated that while the fundamental interval $\left(R_{100}-R_{0}\right)$ remained apparently constant to a few parts in Io 000 , the calibration constants of the thermometer differed from those of the ordinary platinum resistance thermometer so greatly as to necessitate comparison with a standard platinum thermometer at shorter temperature intervals. The most convenient method for doing this seemed to be by using a standardized platinum thermometer immersed in the thermostat bath, comparing this with the calorimeter thermometer by means of the thermocouples when the calorimeter was mounted in the jacket as described above. This thermometer was held in contact with the face of the split-copper bar which incloses the thermocouple junctions, and for protection from sudden local fluctuations in the temperature of the liquid these were all inclosed in a thick walled copper tube surrounded by a glass tube. By adjusting the temperatures of jacket and calorimeter very nearly to equality and using the thermoelements to read the small difference, usually 
only one or two hundredths of a degree, comparisons could be made to an accuracy of about 0 :oor.

From the observations was obtained a series of resistance differences on the calorimeter thermometer corresponding to a series of temperature differences as determined by the standard resistance thermometer. Taking the ratio of each temperature difference to the corresponding difference in resistance, a series of difference factors varying slightly with temperature was obtained, which may be used to convert observed resistance differences into corresponding temperature differences.

A large number of calibrations were made in this way with somewhat disappointing results. A comparison of the results obtained at different times during several months disclosed disagreements of as much as I part in 2000 from the mean without apparent regularity. Although these results were sufficiently accurate for some of the uses to which the calorimeter was to be put, the irregularities were too great to be attributed to accidental experimental errors, ${ }^{5}$ and finally a more systematic examination of the behavior of the thermometer disclosed a marked dependence upon the previous temperature to which the calorimeter had been subjected. If cooled to $-40^{\circ}$ or so, a consistent series of difference factors was found, while if cooled to only $-15^{\circ}$, a different series of consistent factors was found. For still higher initial temperatures still different series were found. The results of this examination are given in Table $I,{ }^{6}$ and shown graphically in Fig. 8.

The peculiarity in the behavior of this thermometer can be explained on the ground of mechanical strain in the platinum wire. A method of construction which would obviate irregular strains would doubtless eliminate the peculiarity.

5 The particular standard resistance thermometer used in most of the experimental work with this calorimeter is B. S. No. 4725. This thermometer is one of the four described in this Bulletin, 9, pp. $483-492$ (B.S. Scientific Paper No. 200), and has the following constants, ice point resistance $\left(R_{0}\right)=25.4750$, fundamental interval $\left(R_{100}-R_{0}\right)=9.9650, \hat{o}$ (as used in the Calendar equation) $=\mathbf{r . 4 8}$.

${ }^{6} K=\frac{\Delta \theta}{\Delta R}=$ the factor for a resistance thermometer by which an observed change in resistance must be multiplied to find the corresponding change in temperature. This factor varies with the temperature and is stated in such a way that, for the difference of any two observed resistances, the factor to be used corresponds to the mean of these resistances. The computation of this factor from the observed constants of platinum resistance thermometers is treated in a paper by Dickinson and Mueller, this Bulletin, 9, p. 483, ${ }_{1913}$ (Scientific Paper No. 200). For determining actual temperatures by means of the built-in thermometer, the values of $K$ given in the table were used, taking the resistance of this thermometer as 31.0135 ohms at the temperature of $0^{\circ}$. 
TABLE 1

Calibration of Thermometer in Calorimeter No. 11510

\begin{tabular}{|c|c|c|c|c|c|c|c|c|}
\hline Date & $\begin{array}{l}\text { Resistance } \\
\text { of } \\
\text { platinum } \\
\text { thermome- } \\
\text { ter No. } 4725\end{array}$ & $\Delta \mathbf{R}_{4725}$ & $\mathbf{K}_{4725}$ & $\Delta \theta$ & $\begin{array}{c}\text { Resistance } \\
\text { of } \\
\text { thermome- } \\
\text { ter } \\
\text { No. } 11510\end{array}$ & $\Delta \mathbf{R}_{11510}$ & $\mathbf{K}_{11510}$ & $\begin{array}{l}\text { Mean re- } \\
\text { sistance of } \\
\text { thermome- } \\
\text { ter } 11510\end{array}$ \\
\hline \multirow{9}{*}{$\begin{array}{c}1914 \\
\text { Sept. } 19 . . .\end{array}$} & Ohms & Ohms & Deglohm & Degrees & Ohms & Ohms & Deglohm & Ohms \\
\hline & 21.84861 & & & & 26.57352 & & & \\
\hline & & 1.07595 & 9.8017 & 10.546 & & 1.31749 & 8.0046 & 27.23226 \\
\hline & & .95097 & 9.8301 & 9.3481 & & 1.16402 & 8.0309 & 28.47302 \\
\hline & 23.87553 & .97617 & 9.8572 & 9.6223 & 29.05503 & 1.19504 & 8.0519 & 29.65255 \\
\hline & 24.85170 & & & & 30.25007 & & & \\
\hline & & 1.06027 & 9.8860 & 10.482 & & 1. 29815 & 8.0746 & 30.89914 \\
\hline & 25.91197 & .95501 & 9.9149 & 9.4688 & 31.54822 & 1.16945 & 8.0968 & 32.13294 \\
\hline & 26.86698 & & & & 32. 71767 & & & \\
\hline \multirow[t]{7}{*}{ Oct. $1 \ldots .}$. & 21. 39239 & & & & 26.01606 & & & \\
\hline & 22.46697 & 1.07458 & 9.7890 & 10.519 & 27.33193 & 1.31587 & 7.9939 & 26.67399 \\
\hline & & 1.07749 & 9.8190 & 10.580 & & 1.31862 & 8.0235 & 27.99124 \\
\hline & 23.54446 & & & & 28.65055 & & & \\
\hline & & 1.06584 & 9.8492 & 10.498 & . & 1.30461 & 8.0468 & 29.30285 \\
\hline & 24.01000 & 1.05427 & 9.8791 & 10.415 & 29.90010 & 1.29030 & 8.0718 & 30.60131 \\
\hline & 25.66457 & & & & 31.24546 & & & \\
\hline \multirow[t]{7}{*}{ Oct. $2 \ldots . .}$. & 24.18314 & & & & 29.42907 & & & \\
\hline & & 99283 & 9.8660 & 9.7953 & & 1.21694 & 8.0491 . & 30.03754 \\
\hline & 25.17597 & 1.06658 & 9.8954 & 10.554 & 30.64601 & 1.30695 & 8.0753 & 31.29948 \\
\hline & 26.24256 & & & & 31.95296 & & & \\
\hline & & 1.05698 & 9.9260 & 10.492 & & 1.29461 & 8.1044 & 32.60026 \\
\hline & 27.29954 & 104695 & 0.9565 & 10.424 & 33.24757 & & 8.1317 & 3388852 \\
\hline & 28.34650 & & , & & 34.52947 & & & \\
\hline \multirow[t]{11}{*}{ Oct. $3 . . .}$. & 28.53673 & & & & 34.76197 & & & \\
\hline & & .99532 & 9.9629 & 9.9163 & & 1.21886 & 8.1357 & 34.15254 \\
\hline & 27.54141 & & & & 33.54311 & & & \\
\hline & & 1.00349 & 9.9338 & 9.9685 & & 1.22861 & 8.1136 & 32.92881 \\
\hline & 26.53792 & 2.03494 & 9.8899 & 20.125 & 32.31451 & 2.49103 & 8.0790 & 31.06899 \\
\hline & 24.50298 & & & & 29.82348 & & & \\
\hline & & 1.03282 & 9.8467 & 10.170 & & 1.26428 & 8.0441 & 29.19134 \\
\hline & 23.47016 & & & & 28.55920 & & & \\
\hline & & 1.04418 & 9.8175 & 10.251 & & 1.27794 & 8.0215 & 27.92023 \\
\hline & 22.42598 & & & & 27.28126 & & & \\
\hline & 21.37093 & 1.05479 & 9. 7607 & 10.324 & 25.98987 & 1. 29103 & 7.9967 & 26.63539 \\
\hline
\end{tabular}


TABLE 1-Continued.

Calibration of Thermometer in Calorimeter No. 11510-Continued

\begin{tabular}{|c|c|c|c|c|c|c|c|c|}
\hline Date & $\begin{array}{c}\text { Resistance } \\
\text { of } \\
\text { platinum } \\
\text { thermome- } \\
\text { ter No. } 4725\end{array}$ & $\Delta \mathbf{R}_{\mathbf{4 7 2 5}}$ & $\mathbf{K}_{4725}$ & $\Delta \theta$ & $\begin{array}{c}\begin{array}{c}\text { Resistance } \\
\text { of } \\
\text { thermome- } \\
\text { ter } \\
\text { No. } 11510\end{array}\end{array}$ & $\Delta \mathbf{R}_{11510}$ & $\mathbf{K}_{11510}$ & $\begin{array}{l}\text { Mean re- } \\
\text { sistance of } \\
\text { thermome- } \\
\text { ter } 11510\end{array}$ \\
\hline \multirow[t]{5}{*}{$\begin{array}{c}1914 \\
\text { Oct. } 6 . . .\end{array}$} & $\begin{array}{c}\text { Ohms } \\
23.53755\end{array}$ & Ohms & Deglohm & Degrees & $\begin{array}{c}\text { Ohms } \\
28.63794\end{array}$ & Ohms & Deglohm & Ohms \\
\hline & 24.56798 & 1.03043 & 9.8485 & 10.1482 & 29.90061 & 1.26267 & 8.0371 & 29.26927 \\
\hline & 25.60421 & 1.03623 & 9.8777 & 10.2356 & 31.16998 & 1.26937 & 8.0635 & 30.53529 \\
\hline & 26.60949 & 1.00528 & 9.9068 & 9.9591 & 32.40146 & 1.23148 & 8.0871 & 31.78572 \\
\hline & $\begin{array}{l}27.60442 \\
21.89236\end{array}$ & 99493 & 9.9357 & 9.8853 & $\begin{array}{l}33.62014 \\
26.62643\end{array}$ & 1.21868 & 8.1115 & 33.01080 \\
\hline \multirow{7}{*}{ Oct. $12 \ldots$} & 22.93753 & 1.04517 & 9.8025 & 10.2453 & 27.90629 & 1.27986 & 8.0050 & 27.26636 \\
\hline & 23.96930 & 1.03177 & 9.8316 & 10.1439 & 29.16943 & 1.26314 & 8.0307 & 28.53786 \\
\hline & 24.98922 & 1.01922 & 9.8604 & 10.0568 & 30.41809 & 1.24866 & 8.0541 & 29.79376 \\
\hline & 25.99801 & 1.00879 & 9.8891 & 9.9760 & 31.65334 & 1.23525 & 8.0761 & 31.03573 \\
\hline & 26.99670 & .99869 & 9.9181 & 9.9051 & 32.87607 & 1.22273 & 8.1008 & 32.26470 \\
\hline & 27.98556 & .98886 & 9.9469 & 9.8361 & 34.08711 & 1.21104 & 8.1220 & 33. 48159 \\
\hline & 28.96861 & .98305 & 9.9756 & 9.8065 & 35.29114 & 1.20403 & 8.1447 & 34.68913 \\
\hline \multirow[t]{8}{*}{ Oct. 13.... } & 20.74645 & & & & 25.22703 & & & \\
\hline & 21.80824 & 1.06179 & 9.7710 & 10.3747 & 26.52656 & 1.29953 & 7.9834 & 25.87679 \\
\hline & 22.85661 & 1.04837 & 9.8002 & 10.2742 & 27.80933 & 1.28277 & 8.0094 & 27.16794 \\
\hline & 23.89337 & 1.03676 & 9.8294 & 10.1907 & 29.07820 & 1.26887 & 8.0313 & 28.44377 \\
\hline & 24.91941 & 1.02604 & 9.8584 & 10.1151 & 30.33392 & 1.25572 & 8.0552 & 29.70606 \\
\hline & 25.93500 & 1.01559 & 9.8873 & 10.0414 & 31.57708 & 1.24316 & 8.0773 & 30.95550 \\
\hline & 26.94079 & 1.00579 & 9.9163 & 9.9737 & 32.80834 & 1.23126 & 8.1004 & 32.19271 \\
\hline & 27.93753 & .99674 & 9.9453 & 9.9129 & 34.02880 & 1.22046 & 8.1223 & 33. 41857 \\
\hline
\end{tabular}


TABLE 1-Continued

Calibration of Thermometer in Calorimeter No. 11510-Continued

\begin{tabular}{|c|c|c|c|c|c|c|c|c|}
\hline Date & $\begin{array}{c}\text { Resistance } \\
\text { of } \\
\text { platinum } \\
\text { thermome- } \\
\text { ter No. } 4725\end{array}$ & $\Delta \mathbf{R}_{\mathbf{4 7 2 5}}$ & $\mathbf{K}_{4725}$ & $\Delta \theta$ & $\begin{array}{c}\text { Resistance } \\
\text { of } \\
\text { thermome- } \\
\text { ter } \\
\text { No. } 11510\end{array}$ & $\Delta \mathbf{R}_{11510}$ & $\mathbf{K}_{11510}$ & $\begin{array}{l}\text { Mean re- } \\
\text { sistance of } \\
\text { thermome- } \\
\text { ter } 11510\end{array}$ \\
\hline \multirow[t]{14}{*}{$\begin{array}{c}1914 \\
\text { Oct. } 15 . . .\end{array}$} & $\begin{array}{c}\text { Ohms } \\
25.69525\end{array}$ & Ohms & Deglohm & Degrees & $\begin{array}{c}\text { Ohms } \\
31.27997\end{array}$ & Ohms & Deglohm & Ohms \\
\hline & 26.20483 & 0.50958 & 9.9023 & 5.0460 & 31.90474 & 0.62477 & 8.0766 & 31.59435 \\
\hline & 26. 71326 & .50843 & 9.9169 & 5.0420 & 32.52780 & .62306 & 8.0923 & 32.21627 \\
\hline & 27.22057 & .50731 & 9.9316 & 5.0384 & 33.14954 & .62174 & 8.1037 & 32.83867 \\
\hline & 27. 72667 & .50610 & 9.9463 & 5.0338 & 33.76957 & .62003 & 8.1186 & 33.45956 \\
\hline & 28.23203 & .50536 & 9.9611 & 5.0339 & 34.38843 & .61886 & 8.1341 & 34.07900 \\
\hline & $\begin{array}{l}28.73643 \\
25.76816\end{array}$ & .50440 & 9.9757 & 5.0317 & $\begin{array}{l}35.00617 \\
31.36791\end{array}$ & .61774 & 8.1453 & 34.69680 \\
\hline & 26.27573 & .50757 & 9.9042 & 5.0271 & 31.99065 & .62274 & 8.0726 & 31.67928 \\
\hline & $\begin{array}{l}26.78281 \\
26.78275\end{array}$ & .50708 & 9.9189 & 5.0297 & $\begin{array}{l}32.61224 \\
32.61211\end{array}$ & .62159 & 8.0917 & 32.30145 \\
\hline & 27.28927 & .50652 & 9.9336 & 5.0316 & 33. 23281 & .62070 & 8.1063 & 32.92246 \\
\hline & 27.79465 & .50538 & 9.9483 & $\begin{array}{r}5.0277 . \\
.\end{array}$ & 33.85223 & .61942 & 8.1168 & 33.54252 \\
\hline & 28.29899 & .50434 & 9.9631 & 5.0248 & 34.47026 & .61803 & 8.1303 & 34.16125 \\
\hline & $\begin{array}{l}28.80230 \\
29.05588\end{array}$ & .50331 & 9.9776 & 5.0218 & $\begin{array}{l}35.08694 \\
35.39775\end{array}$ & .61668 & 8.1433 & 34.77860 \\
\hline & 29.55694 & .50106 & 9.9998 & 5.0105 & 36.01122 & .61347 & 8.1675 & 35.70449 \\
\hline
\end{tabular}

It was found that with suitable regulation of the jacket temperature, calorimetric determinations could be very conveniently made, dispensing with the thermometer in the calorimeter shell, and referring calorimeter temperatures to the standard platinum thermometer in the outside-stirred bath by means of the thermocouples, as described above. This method of observation has therefore been followed in much of the later work. 


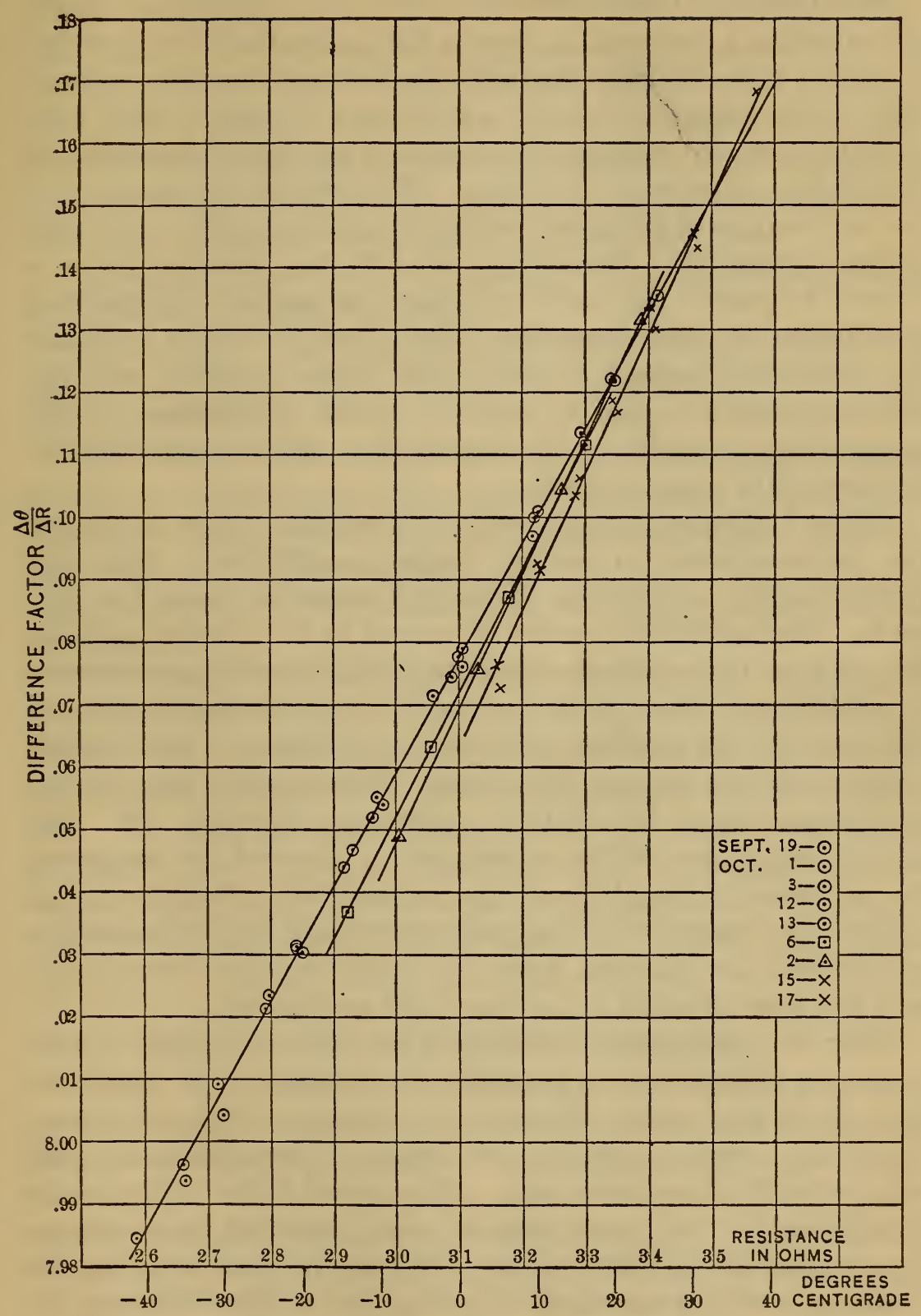

FIG. 8.-Calibration of resistance thermometer in calorimeter 
Heat-Capacity Determinations.-With the calorimeter empty or containing a specimen, in place in the jacket, the latter is cooled by means of the refrigerating coil to the lowest temperature attainable in the apparatus (about $-55^{\circ} \mathrm{C}$ ) and is kept at this temperature until the calorimeter is cooled to the desired temperature for the first experiment of the day. By means of the heating coil the temperature of the jacket is then brought to equality with that of the calorimeter. The setting valve of the thermoregulator is opened to permit the mercury column to assume a position of equilibrium at this temperature, after which the valve is closed. The regulating current is set to the proper amount, and the thermoregulator begins to operate. Final adjustment of the temperature is made by the slow-motion screw controlling the position of the upper contact.

Before beginning the determination sufficient time is allowed for the calorimeter to assume thermal equilibrium. This time rarely exceeds 15 minutes, depending somewhat upon the contents. Meanwhile the current to be used in the calorimeter heating coil is set to the proper value in an auxiliary coil so connected to a quick-throw switch that the current may be instantaneously thrown from the auxiliary coil to the calorimeter. The potentiometer used to measure the current and potential drop in the calorimeter heater is balanced against the standard cell. The initial temperature of the calorimeter is observed by measuring the resistance of the platinum thermometer with the Wheatstone bridge. By means of the special switchboard the galvanometer connections are changed from the bridge to the thermocouple and the zero adjusted to a chosen point on the scale.

After the temperature observation the observer begins to take thermocouple readings at intervals of 30 seconds. At the beginning of the next minute the current is thrown on the calorimeter heater by a second observer, the instant of time being recorded automatically on a chronograph. The current in the jacket heater is increased to the proper amount, and thereafter from time to time adjusted by the observer so as to keep the temperature of the jacket as nearly as practicable equal to that of the calorimeter, as indicated by the thermocouple reading. Potentiometer readings of current and of potential drop in the calorimeter heating coil 
are taken alternately at equal intervals of time throughout the experiment. At the end of a predetermined time interval the current is thrown off and the time again automatically recorded. The jacket is brought under control of the thermostat at the temperature of the calorimeter and after sufficient time has elapsed for the calorimeter to assume equilibrium, its final temperature is observed. There are thus obtained the following data:

(a) The initial and final resistance of the calorimeter thermometer, giving its temperature change.

(b) The series of readings of current and of potential drop in the calorimeter coil during the experiment, giving the rate of energy supplied electrically.

(c) A thermocouple record of temperature difference between calorimeter surface and the surrounding jacket surface, from which is computed the correction. for thermal leakage between calorimeter and its surroundings.

(d) A record of the duration of the energy supply to the calorimeter.

Calibration of Thermocouples.-A supplementary experiment is made to determine the relation between the rate of thermal leakage and the difference in temperature between the surfaces of calorimeter and jacket. This is done only at occasional intervals. To make this determination the temperature of the jacket is altered from that of the calorimeter and at definite intervals of time, alternate readings are taken of the resistance thermometer in the calorimeter, and of the thermocouple between calorimeter and jacket. An approximate knowledge of the heat capacity of the calorimeter permits the computation, from this data, of the rate of thermal leakage in terms of the thermocouple readings.

Sample Heat-Capacity Determination.-An example of the record of a single experiment in determining the heat capacity of the calorimeter is given in Fig. 9. In columns 4 and 5 are recorded the readings of the thermocouple, and of the thermometer resistances corresponding to times recorded in column 3. At the left of the page are recorded the potentiometer readings for determining the potential drop and the current in the calorimeter heating coil. The observations for the duration of the calorimeter heating current are recorded under that heading. 


\section{CALORIMETER RECORD}

Observers N.S.O. and M.S. V.D.

Date Oct. 1s, 1914, Experiment No. 7

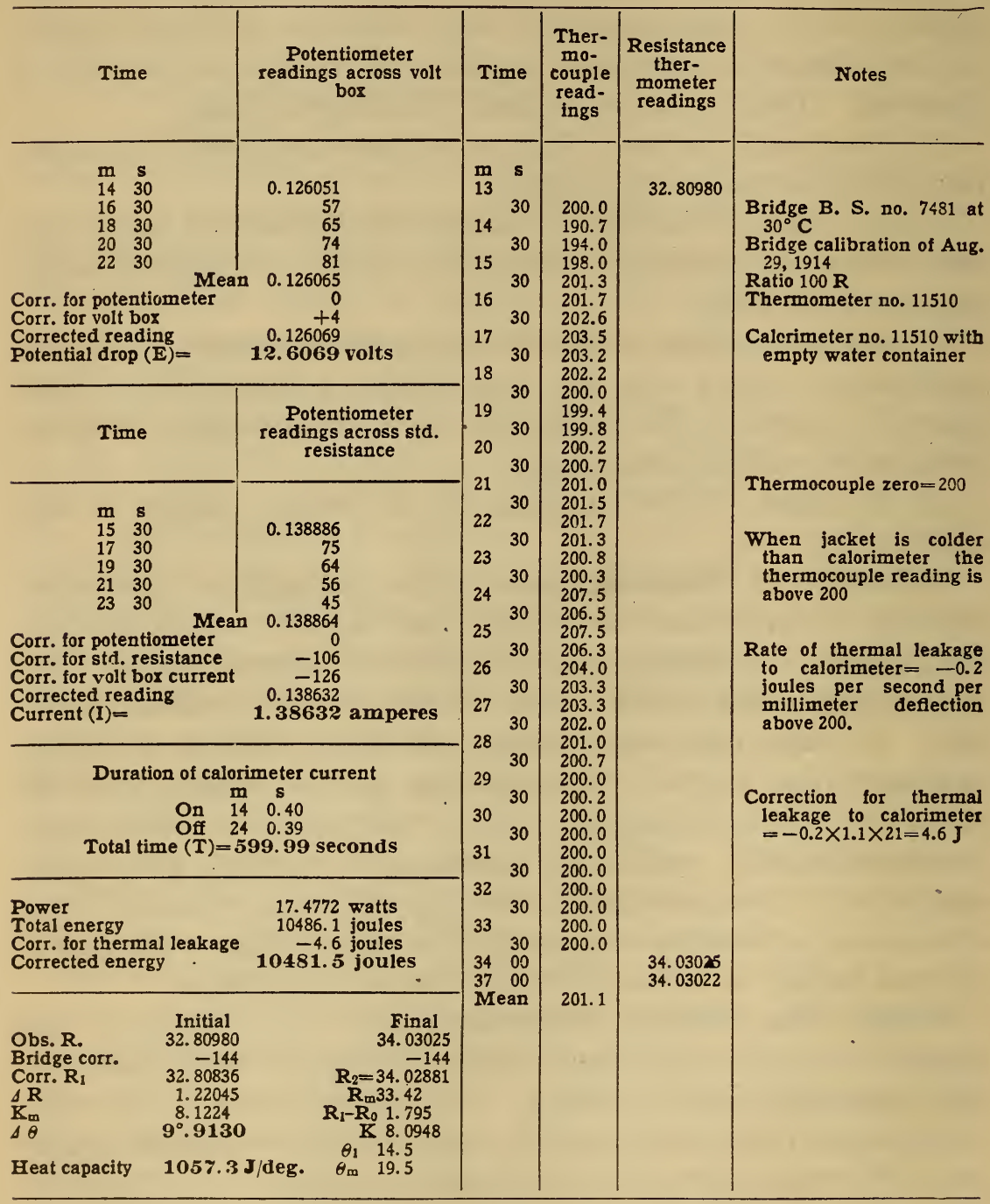

FIG. 9.-Sample heat-capacity determination 
The initial and final readings of thermometer resistance corrected for bridge errors give the initial and final thermometer resistances $R_{1}$ and $R_{2}$. The difference between the initial and final resistances, $\Delta R$, multiplied by the difference factor, $K_{\mathrm{m}}$, gives the change in temperature of the calorimeter, $\Delta \theta$. In obtaining $K_{\mathrm{m}}$ from the chart, Fig. 8, the mean resistance $R_{\mathrm{m}}$ is used.

The average thermocouple deflection multiplied by the rate and by the time between initial and final thermometer readings gives the correction for thermal leakage.

The mean potentiometer readings for potential drop and for current, corrected for instrumental errors, and multiplied by the proper reduction factors, give the potential drop, $E$, and current, $I$. The product of the current and potential drop is the power, and this multiplied by the time is the total energy electrically supplied to the calorimeter. This total energy corrected for thermal leakage gives the corrected energy, i. e., the amount of energy received by the calorimeter and contents during the experiment.

The corrected energy divided by the change in temperature, $\Delta \theta$, gives the heat capacity in joules per degree.

To obtain the mean temperature the initial temperature, $\theta_{1}$, is first computed from $R_{1}$, using $R_{\mathrm{o}}$ for the thermometer resistance at $0^{\circ}$ and the appropriate value of $K$. The initial temperature plus one-half the temperature change gives the mean temperature $\theta_{\mathrm{m}}$.

Method of Computation of Results.-The method of calculation may be summarized as follows:

Supposing the observed data to be corrected for all instrumental errors, the heat capacity of the calorimeter is given by the formula

where

$$
C=\frac{I E T+B i d}{\Delta R K_{\mathrm{m}}}
$$

$C=$ mean heat capacity of calorimeter in joules per degree,

$I=$ current in amperes (mean value),

$E=$ potential drop in volts (mean value),

$T=$ duration of energy supply to calorimeter in seconds,

$d=$ mean thermocouple deflection in millimeters during experiment, 
$t=$ time in minutes between initial and final readings of calorimeter resistance thermometer,

$B=$ rate of thermal leakage to calorimeter from surroundings in joules per minute per $\mathrm{mm}$ thermocouple deflection,

$R_{1}=$ initial resistance of thermometer in ohms,

$R_{2}=$ final resistance of thermometer in ohms,

$\Delta R=$ difference between the initial and final resistances of thermometer in ohms,

$K_{\mathrm{m}}=$ difference factor for the resistance thermometer, i. e., $\frac{\Delta \theta}{\Delta R}$ in degrees per ohm.

The mean temperature of the determination is given by the formula

$$
\theta_{\mathrm{m}}=\left(R_{1}-R_{\mathrm{o}}\right) K+\frac{\Delta \theta}{2}
$$

where

$\theta_{\mathrm{m}}=$ mean temperature,

$K=$ difference factor corresponding to the mean resistance, $1 / 2\left(R_{1}+R_{0}\right)$.

$R_{\mathrm{o}}=$ resistance of thermometer at $\mathrm{O}^{\circ} \mathrm{C}$

The current and the potential drop were always so nearly constant that the approximation in taking the product of their mean values multiplied by the time as the total energy is well within the limit of allowable error.

The values of the factor $K$ were taken from the results of calibrations summarized in Table $I$, page 34 , and plotted in Fig. 8, the difference factor being taken from the proper curve at the point corresponding to the mean thermometer resistance for the observed interval.

Since the performance of the thermometer depended upon its previous thermal treatment, in the use of the chart the appropriate calibration line was chosen to correspond with the initial temperature of the experiments on the particular day.

Results of Heat-Capacity Determinations.-The results of the determinations of the heat capacity of the calorimeter, including the container used for the ice and water samples, are given in 
Table 2 and shown graphically in Fig. Io. Two distinct curves are shown, of which the points on the lower curve are more consistent. The upper curve represents the results obtained before the addition of the second set of couples (p. 28), which indicate the difference between the mean temperature of the inner surface of the jacket and that of the point in the liquid at which the

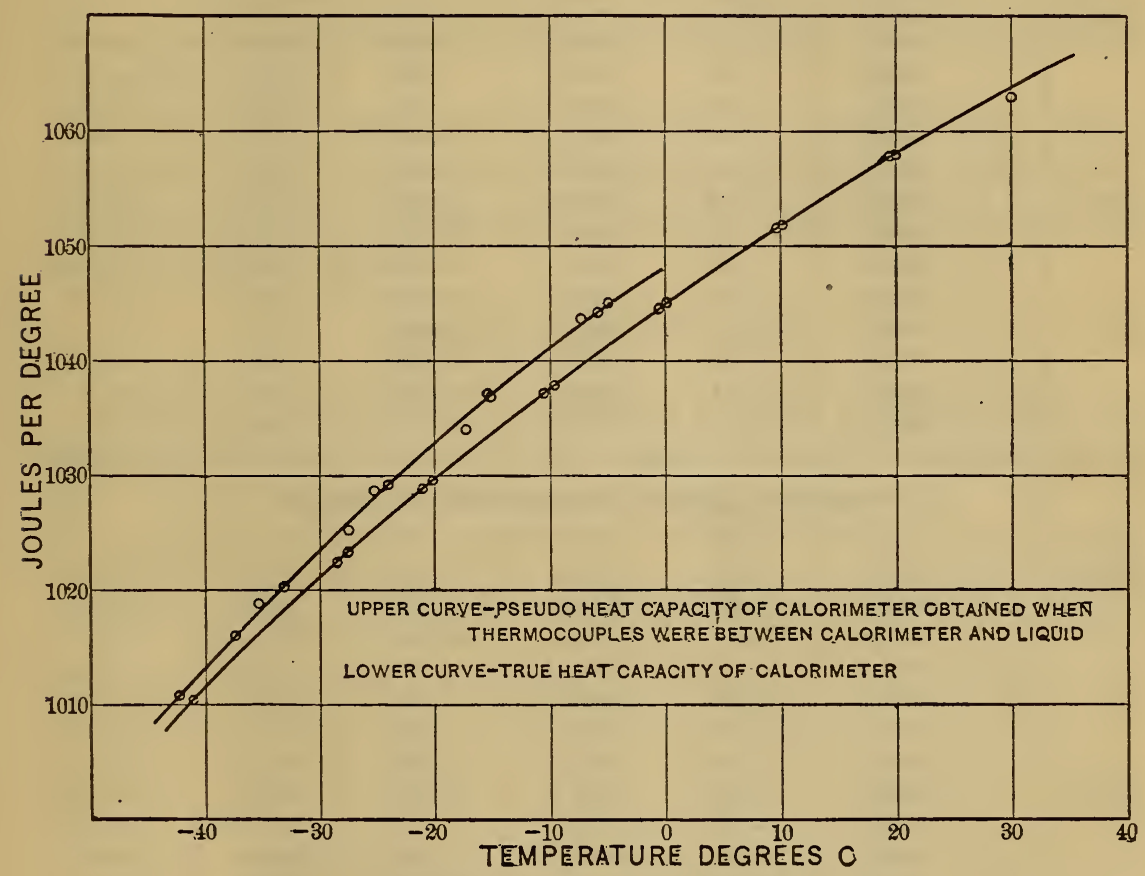

FIG. I0.-Results of heat capacity determinations

other set of junctions is placed. Subsequent experiments made after the second set of couples had been arranged upon the interior surface of the jacket showed that in the earlier arrangement the true difference of temperature between the surfaces of the calorimeter and of the jacket had not been indicated, owing to the effect of lag in the liquid and jacket.

Unfortunately, some determinations of specific heat had been made when the significance of this effect became apparent, but 
TABLE 2

Résumé of Determinations of Heat Capacity of Calorimeter No. 11510

THERMOCOUPLES-CALORIMETER TO LIQUID

\begin{tabular}{|c|c|c|c|c|c|c|c|}
\hline Date & Exp. & Total energy & $\begin{array}{l}\text { Correction } \\
\text { for thermal } \\
\text { leakage }\end{array}$ & $\begin{array}{l}\text { Corrected } \\
\text { intal energy }\end{array}$ & $\begin{array}{l}\text { Temperature } \\
\text { difference }\end{array}$ & $\begin{array}{l}\text { Mean heat } \\
\text { capacity }\end{array}$ & $\begin{array}{c}\text { Mean } \\
\text { temperature }\end{array}$ \\
\hline \multirow[t]{6}{*}{$\begin{array}{c}1914 \\
\text { May } 20\end{array}$} & 1 & $\begin{array}{c}\text { Joules }^{7} \\
9467.3\end{array}$ & $\begin{array}{l}\text { Joules } \\
+10.2\end{array}$ & $\begin{array}{l}\text { Joules } \\
9477.5\end{array}$ & $\begin{array}{l}\text { Deg C } \\
9.3754\end{array}$ & $\begin{array}{c}\text { Joules/deg C } \\
1010.9\end{array}$ & $\begin{array}{l}D e g C \\
-42.30\end{array}$ \\
\hline & 2 & 9469.1 & -2.2 & 9466.9 & 9.2776 & 1020.4 & -32.98 \\
\hline & 3 & 9463.2 & -5.8 & 9457.4 & 9.1883 & 1029.3 & -23.74 \\
\hline & 4 & 9466.1 & -3.8 & 9462.3 & 9.1227 & 1037.2 & -14.58 \\
\hline & 5 & 9465.8 & -3.4 & 9462.4 & 9.0619 & 1044.2 & -5.48 \\
\hline & 6 & 9479.7 & -0.9 & 9478.8 & 9.0334 & 1049.3 & +3.57 \\
\hline \multirow[t]{4}{*}{ July 1} & 1 & 10556.3 & -7.5 & 10548.8 & 10.3509 & 1019.1 & -35.16 \\
\hline & 2 & 10555.3 & -6.8 & 10548.5 & 10.2514 & 1028.9 & -24.86 \\
\hline & 3 & 10555.0 & -4.0 & 10551.0 & 10.1731 & 1037.0 & -14.65 \\
\hline & 4 & 10552.9 & -3.1 & 10549.8 & 10.0938 & 1045.2 & -4.50 \\
\hline \multirow[t]{4}{*}{ July 7} & 1 & 10480.9 & +1.5 & 10482.4 & 10.3164 & 1016.1 & -37.36 \\
\hline & 2 & 10483.6 & -5.2 & 10478.4 & 10.2195 & 1025.4 & -27.08 \\
\hline & 3 & 10485.3 & -2.1 & 10483.2 & 10.1365 & 1034.2 & -16.91 \\
\hline & 4 & 10487.6 & -1.5 & 10486.1 & 10.0473 & 1043.7 & -6.81 \\
\hline
\end{tabular}

THERMOCOUPLES-CAIORIMETER TO JACKET

\begin{tabular}{l|l|l|r|r|r|r|r|r|r}
\hline Oct. 12 & 1 & 10462.1 & 0.0 & 10462.1 & 10.2453 & 1021.2 & -30.14 \\
& 2 & 10445.9 & -0.5 & 10445.4 & 10.1439 & 1029.7 & -19.94 \\
& 3 & 10435.3 & -1.4 & 10433.9 & 10.0568 & 1037.5 & -9.84 \\
& 4 & 10425.3 & -1.0 & 10424.3 & 9.9760 & 1044.9 & +0.18 \\
& 5 & 10416.5 & -3.4 & 10413.1 & 9.9051 & 1051.3 & +10.12 \\
& 6 & 10405.0 & -2.5 & 10402.5 & 9.8361 & 1057.6 & +19.99 \\
& 7 & 10423.2 & -1.8 & 10421.4 & 9.8065 & 1062.7 & +29.80 \\
& 1 & 10483.0 & +0.8 & 10483.8 & 10.3747 & 1010.5 & -41.25 \\
& 2 & 10483.4 & -1.3 & 10482.1 & 10.2742 & 1020.2 & -30.93 \\
& 3 & 10488.1 & -1.8 & 10486.3 & 10.1907 & 1029.0 & -20.70 \\
& 4 & 10489.4 & -2.5 & 10486.9 & 10.1151 & 1036.8 & -10.55 \\
& 5 & 10487.2 & -0.4 & 10486.8 & 10.0414 & 1044.4 & -0.47 \\
& 6 & 10488.0 & -5.6 & 10482.4 & 9.9737 & 1051.0 & +9.54 \\
& 7 & 10486.1 & -4.6 & 10481.5 & 9.9129 & 1057.4 & +19.48 \\
\hline
\end{tabular}

all of this earlier work could be satisfactorily computed as explained below. The value of the observed total heat capacity of the empty calorimeter and of the calorimeter containing a specimen would be affected to the same extent by the improper placing of

7 The joule used in this paper is defined by the relation $\frac{e^{2}}{R}$, where $R$ is in international ohms and $e$ is in international volts, determined by the relation emf of mean Weston normal cell at $20^{\circ} \mathrm{C}$ equals r.or 830 volts: the international $\mathrm{ohm}$ is the resistance offered to an unvarying current by a column of pure mercury at $0^{\circ} \mathrm{C}$ of length $106.300 \mathrm{~cm}$ and uniform cross section such that the mass is 14.4521 grams. 
the thermocouple, provided that, in the two experiments, the manipulation of the jacket was similar. If, therefore, in computing the result of a specific heat determination, a value of heat capacity of the calorimeter be used, determined under experimental conditions similar to those in the specific heat determination, no error is introduced into the resulting value of specific heat. It was necessary, therefore, to employ the false values of heat capacity shown by the upper curve of Fig. Io in computing the earlier results.

It was ascertained that the variations in manipulation which did occur, such as the use of different amounts of refrigeration and compensating heating, etc., were not sufficient to cause any large systematic error.

\section{SPECIFIC HEAT OF WATER}

In Table 3 are given the results of a series of experiments on the specific heat of water in the range $0^{\circ}$ to $40^{\circ} \mathrm{C}$ made with a view to testing the performance of this calorimeter. Fig. I I shows the same results graphically. These determinations were not undertaken with the idea of establishing authoritative values of this important constant. A great amount of experimental data on this constant, obtained by this and other methods, has been accumulated in the course of the calorimetric investigations carried out at the Bureau during the past three years, but in view of the discrepancies between the most carefully conducted researches published to date it seems that further publications are hardly warranted until the investigations can be regarded as exhaustive with the experimental methods at command.

The experiments were made in connection with observations on the specific heat and latent heat of ice in the same calorimeter, ${ }^{8}$ so that the specific heat of water at temperatures near the freezing point, where the published results are very discordant, was of some immediate interest. Observations were made, except in one instance, using the same samples of water which had previously been experimented on as ice.

${ }^{8}$ Dickinson and Osborne, this Bulletin, 12, p. 49; r9r5.

$6844^{\circ}-15-4$ 


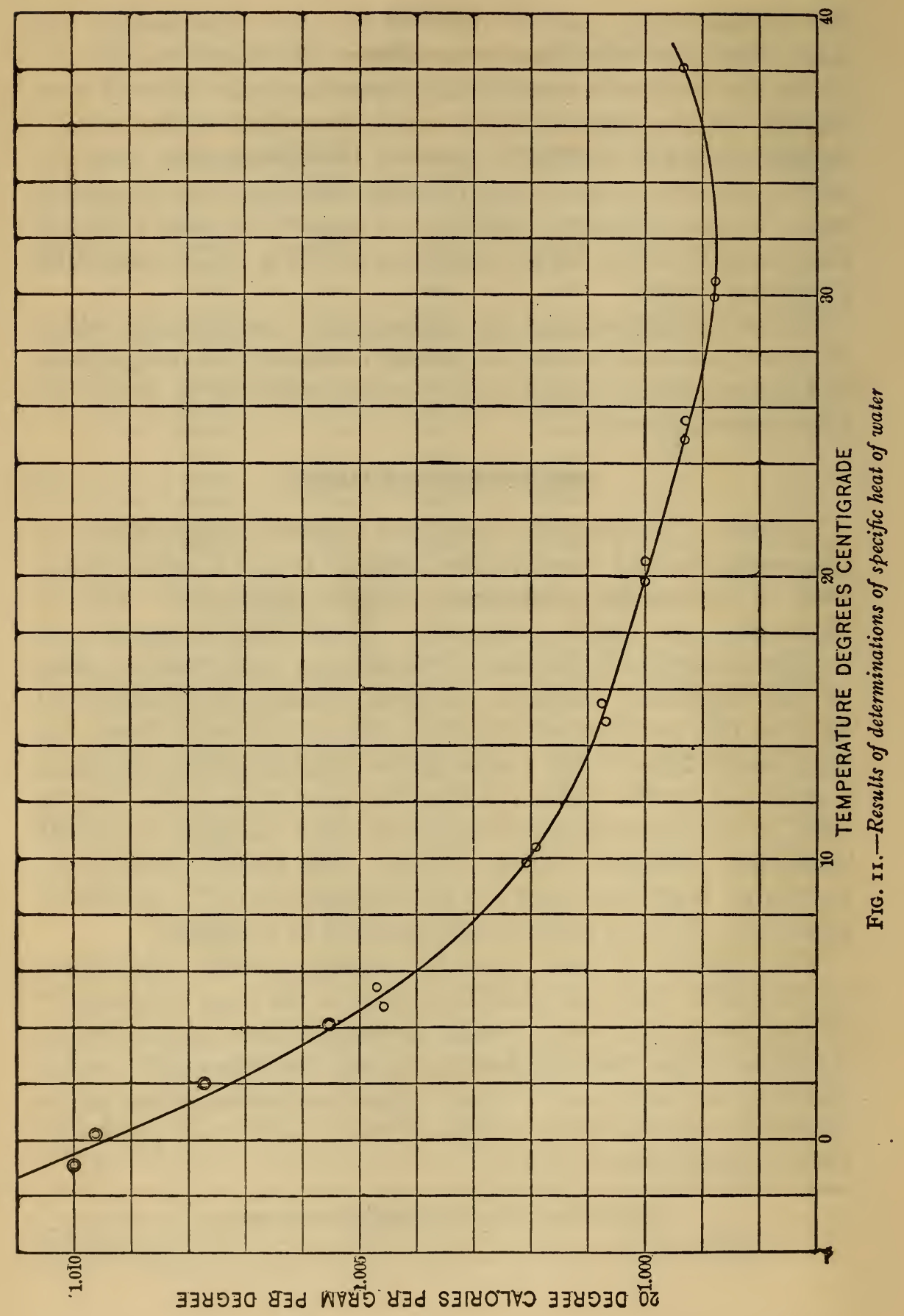


TABLE 3

Specific Heat of Water

\begin{tabular}{|c|c|c|c|c|c|c|c|c|c|c|c|}
\hline Date & Exp. & Energy & Corr. & $\begin{array}{l}\text { Cor- } \\
\text { rected } \\
\text { energy }\end{array}$ & $\begin{array}{c}\text { Temp. } \\
\text { diff. }\end{array}$ & $\begin{array}{l}\text { Heat } \\
\text { capacity } \\
\text { cal. and } \\
\text { contents }\end{array}$ & $\begin{array}{c}\text { Heat } \\
\text { capacity } \\
\text { calori- } \\
\text { meter }\end{array}$ & $\begin{array}{c}\text { Heat } \\
\text { capacity } \\
\text { con- } \\
\text { tents }\end{array}$ & $\frac{J}{g \cdot d e g .}$ & $\begin{array}{c}\text { Specific } \\
\text { heat }\end{array}$ & $\begin{array}{l}\text { Mean } \\
\text { tem- } \\
\text { pera- } \\
\text { ture }\end{array}$ \\
\hline 1914 & & de & & oules & Deg. C & Jldeg & Jldeg & J/deg. & & $\begin{array}{c}\text { Calories } \\
20^{\circ}\end{array}$ & ${ }^{\circ} \mathrm{C}$ \\
\hline \multirow[t]{6}{*}{ Oct. 15} & 1 & 16733.6 & +30.2 & 16763.8 & 5.0460 & 3322.2 & 1047.9 & 2274.3 & 4.2020 & 1.0046 & +4.70 \\
\hline & 2 & 16729.1 & +9.7 & 16738.8 & 5.0420 & 3319.9 & 1051.2 & 2268.7 & 4. 1916 & 1.0021 & 9.74 \\
\hline & 3 & 16719.8 & +6.5 & 16726.3 & 5.0384 & 3319.8 & 1054.3 & 2265.5 & 4.1857 & 1.0007 & 14.78 \\
\hline & 4 & 16716.2 & +2.2 & 16718.4 & 5.0338 & 3321.2 & 1057.3 & 2263.9 & 4.1827 & 1.0000 & 19.82 \\
\hline & 5 & 16714.5 & +10.4 & 16724.9 & 5.0339 & 3322.5 & 1060.3 & 2262.2 & 4.1796 & 9993 & 24.78 \\
\hline & 6 & 16713.7 & +11.4 & 16725.1 & 5.0317 & 3323.9 & 1062.8 & 2261.1 & 4.1776 & 9988 & 29.90 \\
\hline \multirow[t]{7}{*}{ Oct. 17} & 1 & 16701.8 & +2.8 & 16704.6 & 5.0271 & 3322.9 & 1048.3 & 2274.6 & 4.2025 & 1.0047 & +5.40 \\
\hline & 2 & 16698.9 & -1.0 & 16697.9 & 5.0297 & 3319.9 & 1051.7 & 2268.2 & 4. 1907 & 1.0019 & 10.45 \\
\hline & 3 & 16702.1 & +3.6 & 16705.7 & 5.0316 & 3320.1 & 1054.3 & 2265.8 & 4.1862 & 1.0008 & 15.47 \\
\hline & 4 & 16698.5 & +2.6 & 16701.1 & 5.0277 & 3321.8 & 1057.8 & 2264.0 & 4.1829 & 1.0000 & 20.51 \\
\hline & 5 & 16699.4 & -2.2 & 16697.2 & 5.0248 & 3323.0 & 1060.7 & 2262.3 & 4.1798 & .9993 & 25.53 \\
\hline & 6 & 16696.0 & -3.2 & 16692.8 & 5.0218 & 3324.1 & 1063.2 & 2260.9 & 4.1776 & 9988 & 30.54 \\
\hline & 7 & 16683.7 & -0.5 & 16683.2 & 5.0105 & 3329.6 & 1067.1 & 2262.5 & 4.1801 & .99935 & 38.10 \\
\hline Sept. 9 & 1 & 15040.2 & +7.2 & 15047.4 & 5.0318 & 2990.5 & 1044.1 & 1946.4 & 4.2248 & 1.0100 & -0.925 \\
\hline Sept. 8 & 1 & 14675.1 & +17.0 & 14692.0 & 4.9130 & 2990.5 & 1044.9 & 1945.6 & 4.2229 & 1.0096 & +0.237 \\
\hline Aug. 28 & 1 & 30146.3 & +34.1 & 30180.4 & 10.100 & 2988.1 & 1046.1 & 1942.0 & 4.2153 & 1.0078 & +2.026 \\
\hline Sept. 9 & 2 & 15012.0 & +9.6 & 15021.6 & 5.0316 & 2985.3 & 1047.5 & 1937.8 & 4.2062 & 1.0056 & +4.110 \\
\hline
\end{tabular}

A comparison of the results given above with the unpublished results of a long series of experiments, made at the Bureau, using a stirred water calorimeter in the temperature range from $10^{\circ}$ to $40^{\circ}$, shows an agreement at all points within about I part in 2000. The results of October 15 and 17 (Table 3 ) in the interval $5^{\circ}$ to $38^{\circ}$ were obtained using the standard platinum resistance thermometer. Those of August 28 to September 9 were obtained using only the thermometer in the walls of the calorimeter. The latter results appear somewhat less consistent than the former, yet serve adequately to extend the curve beyond the freezing point and to indicate that no peculiarity exists in the specific heat of water at zero degrees.

\section{SUMMARY}

A calorimeter consisting of a cylindrical copper vessel in the walls of which are embedded a coil of resistance wire to supply heat electrically, and a platinum resistance coil for use as a thermometer, has been found useful over a wide range of temperatures and is applicable to a variety of problems. 
For use at low temperatures the calorimeter is mounted in a jacket surrounded by a bath of gasoline the temperature of which can be controlled thermostatically to within a few thousandths of a degree at any temperature between $-55^{\circ}$ and $+40^{\circ} \mathrm{C}$, or can be changed rapidly in order to keep it the same as that of the calorimeter when heat is being supplied to the latter.

Differences in temperature between the surface of the calorimeter and that of the jacket are measured by means of multiple thermocouples which have ro junctions distributed over the surface of each.

The platinum resistance coil embedded in the calorimeter shows slight irregularities in its behavior, probably due to the difference in expansion between the platinum and the copper which surrounds it. Uncertainties on this account, while in general negligible, can be avoided by measuring the temperature of the outer bath with a standard resistance thermometer, using the thermocouples to measure the small difference, usually not more than a few thousandths of a degree, between the calorimeter and the jacket. The thermometer could probably be improved by changing the construction.

Results of a series of experiments give the constants of the resistance thermometer and the heat capacity of the calorimeter, including a tin-lined cell for use in determining the specific heat of ice and water and the latent heat of fusion of ice.

A series of check experiments on the specific heat of water show the order of reproducibility of results which can be obtained with this calorimeter to be I part in 2000 . Measurements made at temperatures between $0^{\circ}$ and $40^{\circ} \mathrm{C}$ gave results which agree to within the limits of experimental accuracy with the unpublished results of a long series of experiments made in the usual form of stirred water calorimeter. The results are also in satisfactory agreement with the most probable values deducible from the data of the most careful investigations published by other observers.

Washington, D. C., February 25, I915. 